\title{
Age at sexual initiation and factors associated with it among youths in North East Ethiopia
}

\author{
Fekadu Mazengia $^{1}$, Alemayehu Worku'2
}

\begin{abstract}
Background: For behavioral as well as physiological reasons, early sexual debut increases young peoples' risk for infection with HIV and other STIs. Youths who begin sexual activity early are more likely to have high-risk sex or multiple sexual partners and are less likely to use condoms. It is crucial to understand the factors associated with early sexual initiation in a broader context for designing and implementing effective interventions targeting youth.

Objective: The objective of the study was to determine the median age at first sexual intercourse and the associated factors of sexual initiation among rural and urban youths (age 15- 24 years).

Methods: A comparative cross sectional study was conducted between, March 1 -15, 2008, in Dessie town and Dessie Zuria Woreda. To draw a total sample of size 1294 (647 urban and 647 rural), a multistage cluster sampling was used. Bivariate and multivariate analyses were employed. Moreover, Kaplan Meier survival analysis was used to estimate the probability of sexual initiation at various age stratified by residence and sex.

Result: About half, 51.3\% of the youths have ever had sex. Rural youths initiate sexual intercourse at lower age than their urban counterparts with mean $( \pm \mathrm{SD})(16.49 \pm 2.11)$ for rural and $(17.18 \pm 2.32)$ for urban youths. The median age at sexual debut was 16 years for rural and 17 years for urban. The hazard ratio for sexual imitation was significant (AHR $[95 \% \mathrm{CI}]=1.45[1.19,2.55]$. Multivariate analysis showed that being female by gender $(\mathrm{AOR}[95 \% \mathrm{CI}]=1.56[1.11$, 2.19]), chewing Khat (AOR [95\% CI] $=2.05$ [1.05, 3.96]), drinking alcohol (AOR [95\% CI] = 2.16 [1.12, 4.18]), watching pornographic materials at age $<18$ years $(\mathrm{AOR}[95 \% \mathrm{CI}]=24.13[3.28,177.80])$ and being less connected with parents $(\mathrm{AOR}[95 \% \mathrm{CI}]=2.30[1.35,3.91])$ were associated with early sexual initiation.

Conclusion and Recommendation: Early sexual initiation prevails more in rural than urban youths. Delaying sexual debut can be achieved through well designed sexual education programs at earlier life. Strengthening the norm of virginity should be advocated. Equally, ways to access condoms and other contraceptives especially to rural youths should be sought for those who already initiate sexual intercourse. [Ethiop. J. Health Dev. 2009;23(2):154-162]
\end{abstract}

\section{Introduction}

Meeting the needs of youth today is critical for a wide range of policies and programs, because the actions of young people will shape the size, health, and prosperity of the world's future population. More than 1 billion people in the world are between the ages of 15 and 24, and most live in developing countries (1-3).

Early sexual debut increases young peoples' risk for infection with HIV and other STIs. Youth who begin early sexual activity are more likely to have high-risk sex or multiple partners and are less likely to use condoms (3). Early childbearing has been linked to higher rates of maternal and child morbidity and mortality, truncated educational opportunities, and lower future family income, larger family sizes, which in turn may lead to greater population growth (4-6). One in every 10 births and one in 10 abortions worldwide and 1 in 6 births in developing countries is to women age between 15-19 years. Each day half a million of young people are infected with a sexually transmitted disease (5). Nearly 12 million young people are living with HIV/AIDS; and more than 7,000 young people become infected with HIV every day (2).

Ethiopia has a very young population; $40 \%$ of its inhabitants are younger than 15 years. Ethiopia faces a very rapid population growth; with an estimated 2.6 million additional people a year. This places serious challenges for poverty reduction and development (7). Early age at marriage and extremely low use of contraceptives are key behavioral factors contributing to the high fertility in a country (8). One of the most important factors influencing Reproductive Health (RH) status of Ethiopians is poverty. Today it is estimated that $47 \%$ of the population live below the poverty line. Young people are among the groups most affected as they have very limited access to employment (7). According to a report by the Ministry of Labor and Social Affairs, 87\% of all registered job seekers are between the ages of 1529 years. Young people in rural areas are increasingly migrating to urban centers. Migration increases the risks of exploitation and sexual violence $(7,9)$.

According to Ethiopian Demographic and Health Survey (EDHS) 2005; among women age 25-49, 32\% had sexual intercourse before age 15, $65 \%$ before age 18, and by age 25 most Ethiopian women have had sexual intercourse. In Ethiopia, trends in age at sexual initiation have increased little between 2000 and 2005 EDHS (4). The median age of marriage for women between 25-49 in Ethiopia is 16.1 years, indicating that for most girls, marriage drives sexual debut $(10,11)$.

The 2007 Epidemiological Synthesis study found that young populations, especially never-married sexually-

${ }^{1}$ College of Medicine and Health Sciences University of Gondar P.O. Box196, E-mail fekiema23@yahoo.com;

${ }^{2}$ School of Public Health, Addis Ababa University P.O.Box 9086, Addis Ababa, Ethiopia 
active females carry the greatest risk of HIV infection in the country, with prevalence rates much higher than the average for both urban and rural areas as well as all women of reproductive age. Girls are at a much greater risk at early ages because of both biological and cultural factors. Young girls in Ethiopia are more vulnerable to HIV than boys because of early age at sexual debut, early marriage, sexual abuse and violence, such as rape and abduction. Sexual mixing patterns are more important than the age at sexual debut in putting girls at higher risk of HIV than boys. As well, adolescent girls are at risk because they are unlikely to have had any training or experience in sexual negotiation skills, and are especially vulnerable in situations with older men where age, wealth, physical strength and other power dynamics put them at a disadvantage (12).

The very low level of economic development, widespread poverty, very poor and inadequate health services make the consequences of adolescent sexuality much more serious in the Ethiopian context than those of the developed countries. This is reflected by the highest HIV prevalence in the group $15-24$ years $12.1 \%, 6 \%$ $9 \%$ among young men aged 15-24, and 10\%-13\% among young women in the same age group) $(12,13)$. The ensuing high rates of unintended pregnancy, abortion, HIV/AIDS and other sexually transmitted infections (STIs) among teenagers make it imperative that, among other things, there is a need to understand and assess the factors that are associated with early or late sexual initiation. Effective implementation of International Conference on Population and Development (ICPD) recommendation on adolescent sexual and reproductive health also requires an understanding of the causes and consequences of early initiation of reproductive-related behaviors. It is crucial for designing and implementing effective interventions targeting youths. The aim of this study therefore is to examine the various paths of the commencement of first sex.

\section{Methods}

A comparative cross-sectional study was conducted in Dessie town and Dessie Zuria rural Woreda of South Wollo Zone, Amhara National Regional State, North East Ethiopia. Dessie is the capital town of South Wollo zone located $400 \mathrm{Km}$ north of Addis Ababa. According to the 1994 National Population and Housing Census of Ethiopia, the population of the town, in 2007 is projected to be 177,116 (14). Dessie town has 20 kebeles. The Health system is represented by one regional hospital, one health center and six governmental health posts. In addition, there are five higher clinics, one general hospital, two medium clinics and nine lower clinics owned by private sectors. Youths (age group 15-24) are estimated to be 39,600 ( $22 \%$ of the total population). Dessie Zuria rural Woreda has 31 rural Kebeles, and the total population is projected to be 278,725 in June 2007. The rural Woreda has 1 health center and 21 health posts.
The data were collected from March 1 to March 15, 2008.

A sample size was obtained using sample size calculation for comparative cross-sectional study. Residence being from urban and rural was considered as main factor for early sexual initiation and used for sample size determination. Assuming a prevalence of early sexual initiation before 18 years for rural youths $60.2 \%$ (from previous study) and $10 \%$ lower in the urban areas (from similar studies), i.e. assuming for urban youths a prevalence of $50 \%(15,16)$, a power of $80 \%$ to detect the above difference, a $5 \%$ type I error, a $10 \%$ non response rate and a design effect of 1.5 for the multistage nature of the sampling technique, a sample size of 1294 (647 from each urban and rural area) was required for the study.

A multistage cluster sampling was used. A total of 12 kebeles (6 urban and 6 rural kebeles) were randomly selected by lottery method. Ten kebeles surrounding Dessie town were purposely excluded to avoid behavioral contamination from urban to rural youths. Each kebele has around 5000 population in approximately 1000 households. Assuming that the kebeles have uniform number of households, from each kebele 108 households were selected using systematic random sampling with a sampling interval of 10. All 15-24 in the selected households were studied.

A semi-structured pre-tested standardized questionnaire was utilized for data collection. The instrument was first prepared in English, translated to Amharic and back to English again. The instrument was pre-tested for consistency of responses after selecting one town and one rural kebele which were not included in the main study. After analyzing the pre-test result necessary modifications were made accordingly before using it in the actual survey. There were 2 supervisors who were nursing students. Eight data collectors were assigned. One day intensive training was given to the data collectors and supervisors before the pretest had been undertaken. The interviewers were the same gender of the respondents in order to decrease embarrassment as some of the questions were about personal sexual lifestyle issues. The supervisors and principal investigator had closely followed the day-to-day data collection process and ensure completeness and consistency of the collected questionnaire daily.

Data were cleaned, coded and entered, in to EPI INFO version 3.3 for windows and analyzed using SPSS for Windows versions 15.0. Both descriptive and analytical statistical procedures were utilized. Proportions and mean values along with 95\% confidence intervals were calculated. T- test for two independent samples was used to assess whether there is significant difference between urban and rural parents score on connectedness with family. Kaplan-Meier (KM) analysis was utilized to estimate the probability of sexual debut at a given age

Ethiop. J. Health Dev. 2009;23(2) 
and Cox proportional hazards model was used by taking not having sex as an outcome variable and age as a follow up period. Moreover, logistic regression was employed to assess possible factors for sexual initiation. Statistical significance was declared if the P-value is less than 0.05 .

Ethical clearance was obtained from the Faculty of Medicine of Addis Ababa University. Officials at different levels including Dessie town municipality and administrative office and selected Woredas and Kebeles were communicated through formal letters by the SPH, AAU. Participants were informed about the purpose and objective of the study. They were also told that they have every right to discontinue or refuse to participate in the study and verbal consent was obtained from each study participant. Confidentiality of the information was assured and privacy was maintained.

\section{Operational Definitions}

- Age at sexual initiation: is age at first intercourse (vaginal penile penetration) other non-intercourse sexual contacts (Kissing, dating \& Men who have sex with Men) were not included.

- Early sexual initiation was taken as an experience of first intercourse before 18 years of age.

- Parent teen connectedness: There were twelve questions to measure parent teen connectedness; each had three points Likert Scale. The questions were broken up in to three variables: family connectedness, family supervision and family norms.

\section{Results}

\section{Socio-demographic characteristics}

A total of 1236 youths participated in the study, giving a response rate of $95.5 \%$. Six hundred and twenty seven of the respondents $(50.7 \%)$ were from rural Kebeles. Male to female ratio was $0.97: 1.02$. Fifty seven percent of youths were between 15-19 years with a mean age of 19.4 years $(\mathrm{SD}=2.7)$. Islam was the dominant religion in rural Kebeles, $82.8 \%$, while majority of urban youths were Christians, 58.5\%. About thirty percent of rural youths had high school and above education, while $78.8 \%$ of their urban counterparts had high school and above education. The majority, $79.1 \%$ of youths were not ever married, $37 \%$ of youths were not enrolled in school at the time of the survey, and $25.4 \%$ had some job for pay. Concerning family structure, $67 \%$ of adolescents grew up in their family with both biological parents up to age 14. Forty eight percent of the participants had illiterate mothers with rural urban prevalence of $67.5 \%$ and $28.2 \%$, respectively. For those youths who were able to list their family income nearly half of the youth parents have income of less than 500 ETB per month.

\section{Median age of sexual initiation and Sexual Behavior}

Fifty one percent of the surveyed youths with almost equal proportion between rural and urban, $49.8 \%$ and $51.3 \%$, have ever had sex. The Mean \& median age of sexual initiation in this study were 16.8 years $(\mathrm{SD}=2.25)$ and 17 years, respectively (Range 8-24 years). First sex was initiated mainly with husband or wife among rural youths, $41 \%$, while for urban counter parts were with girl or boy friend, $32 \%$. High risk sexual initiation was noted among the study participants, $2.4 \% \& 8.7 \%$ initiated their first sex with CSW and causal partner, respectively. Moreover first sexual practices were unplanned in $39 \%$ of the respondents and among these $65 \%$ were unprotected. Sixty one percent of youths started their sexual intercourse before age of 18 (Table 1).

Cox proportional hazards model for not having sex using age as a follow up period showed the hazards of starting sex earlier was higher for rural youths than urban with adjusted hazard ratio [(AHR) $(95 \% \mathrm{CI}))=1.447$ (1.165-1.797) or the Probability of rural youths to start sex earlier was $60 \%$ with CI of $(54 \%, 71 \%)]$. Furthermore, the probability of not having sex up to age 18 is $40 \%$. Figure 1 shows the Kaplan Meier (KM) survival curve for rural and urban female youths indicated a wide gap between the two residency areas. KM plot for males however, didn't show a significant difference between rural and urban males (Fig. 2). The age at sexual debut was higher among males [(mean $[95 \% \mathrm{CI}]=17.22[16.98-17.00])$ than the females (mean $[95 \% \mathrm{CI}]=16.47(16.22-16.71)]$ and the difference was significant $(\mathrm{P}=0.012)$.

Among those who were sexually active the main reasons for them to engage in sex at the first time were marriage for $41 \%$ of rural and $25 \%$ of urban youths, followed by curiosity for $14.7 \%$ of rural and $23.9 \%$ of urban youths, respectively. Being cheated, after using drugs/alcohol, and rape were reported for $10.9 \%, 6.2 \%$ and $6.9 \%$ of initiations, respectively. Among Youths who were not sexually active the main reason for their abstinence were waiting until marriage $40 \%$ of urban and $25 \%$ of rural youths. Other reasons mentioned for not sexually active were fear of sexually transmitted disease including HIV, to wait till getting older and religious value.

Two third of the sexual initiations were unprotected and some occur with higher risk groups. Half of the sexually active youths had more than one sexual partner in their life time. The proportion of youths who reported to have multiple partners in the last 12 months was dropped to $36 \%$ from life time number of multiple partnership 56\%. The mean \pm SD number of partners in the last twelve months and in life time were $1.63 \pm 1.7$ and $2.55 \pm 2.4$, respectively. Of the sexually active youths, $14.2 \%$ had sex with a non-regular (causal) sexual partner. Although two third of the youth ever used condoms, only $36 \%$ of these used it regularly. Twenty nine percent of male respondents had sex with commercial sex workers in the 12 months period prior to the survey and 37\% hadn't use condom consistently. There was significant variation in condom use among rural and urban boys. Seventy seven percent of the rural boys used condom consistently, while 
only $50 \%$ of their urban counterparts used condom regularly when they made sexual intercourse with CSW (Table 1).

\section{Factors of sexual initiation: Socio-demographic}

Socio-demographic characteristics, particularly gender, place of residence and age, were significantly related with early sexual debut. Rural youths were found to engage in sexual intercourse earlier than their urban counterparts (Adjusted OR [95\% CI] 1.75 [1.19, 2.55]). Gender being female (Adjusted OR [95\%CI] =1.56 [1.11, $2.19]$ ), and younger age group (Adjusted OR [95\%CI] $2.82[1.95,4.08]$ were tend to initiate sexual intercourse earlier. Moreover, being in marital union and having less educational status were more likely to be early sexual initiators (Table 2).

\begin{tabular}{|c|c|c|c|}
\hline Variable & $\begin{array}{l}\text { Rural } \\
\text { n (\%) }\end{array}$ & $\begin{array}{l}\text { Urban } \\
\text { n (\%) }\end{array}$ & $\begin{array}{l}\text { Total } \\
\text { n (\%) }\end{array}$ \\
\hline \multicolumn{4}{|l|}{ Ever had sex } \\
\hline Yes & $312(49.8)$ & $322(52.9)$ & $634(51.3)$ \\
\hline No & $315(50.2)$ & $287(47.1)$ & $602(48.7)$ \\
\hline \multicolumn{4}{|l|}{ Age at first sex $(n=634)$} \\
\hline$<=10$ years & $1(0.3)$ & $3(0.9)$ & $4(0.6)$ \\
\hline $10-14$ years & $39(12.5)$ & $28(8.7)$ & $67(10.6)$ \\
\hline $15-19$ years & $222(71.2)$ & $210(65.2)$ & $432(68.1)$ \\
\hline $20-24$ years & $50(16.0)$ & $81(25.2)$ & $131(20.7)$ \\
\hline \multicolumn{4}{|l|}{ Relation of the first partner $(n=634)$} \\
\hline Husband/wife & $128(41.0)$ & $78(24.2)$ & $206(32.5)$ \\
\hline Girl fried/Boy friend & $84(26.9)$ & $103(32.0)$ & $187(29.5)$ \\
\hline Friend & $24(7.7)$ & $38(11.8)$ & $62(9.8)$ \\
\hline Cohabitant & $27(8.7)$ & $58(18.0)$ & $85(13.4)$ \\
\hline Relative & $18(5.8)$ & $6(1.9)$ & $24(3.8)$ \\
\hline Causal & $22(7.1)$ & $33(10.2)$ & $55(8.7)$ \\
\hline Commercial sex workers & $9(2.9)$ & $6(1.9)$ & $15(2.4)$ \\
\hline \multicolumn{4}{|l|}{ First sex was planned $(n=634)$} \\
\hline Planned & $192(61.5)$ & $194(60.2)$ & $386(60.9)$ \\
\hline Unexpected & $120(38.5)$ & $128(39.8)$ & $248(39.1)$ \\
\hline \multicolumn{4}{|l|}{$\begin{array}{l}\text { Discuss about contraceptive } \\
\text { before sex }\end{array}$} \\
\hline Yes & $68(21.8)$ & $103(31.9)$ & $171(26.9)$ \\
\hline No & $229(73.4)$ & $215(66.6)$ & $444(69.9)$ \\
\hline Don't remember & $15(4.8)$ & $5(1.5)$ & $20(3.1)$ \\
\hline \multicolumn{4}{|l|}{ Contraceptive use at first sex } \\
\hline Yes & $77(24.7)$ & $125(38.8)$ & $202(31.9)$ \\
\hline No & $220(70.5)$ & $192(59.6)$ & $412(65.0)$ \\
\hline Don't remember & $15(4.8)$ & $5(1.6)$ & $20(3.2)$ \\
\hline \multicolumn{4}{|l|}{ FP methods at first sex } \\
\hline Condom only & $35(44.3)$ & $62(48.1)$ & $97(46.6)$ \\
\hline Natural methods & $4(5.1)$ & $9(7.0)$ & $13(6.3)$ \\
\hline OCPS & $15(19.0)$ & $20(15.5)$ & $35(16.8)$ \\
\hline Indictable & $25(31.6)$ & $38(29.5)$ & $63(30.3)$ \\
\hline \multicolumn{4}{|l|}{$\begin{array}{l}\text { Partner age at } 1^{\text {st }} \text { sex compared } \\
\text { with girls age }\end{array}$} \\
\hline $\begin{array}{l}\text { Equal or up to } 10 \text { years older than } \\
\text { girls age }\end{array}$ & $96(74.4)$ & $108(76.6)$ & $204(75.6)$ \\
\hline $\begin{array}{l}\text { More than } 10 \text { years older than } \\
\text { girls age }\end{array}$ & $33(25.6)$ & $33(23.4)$ & $66(24.4)$ \\
\hline
\end{tabular}




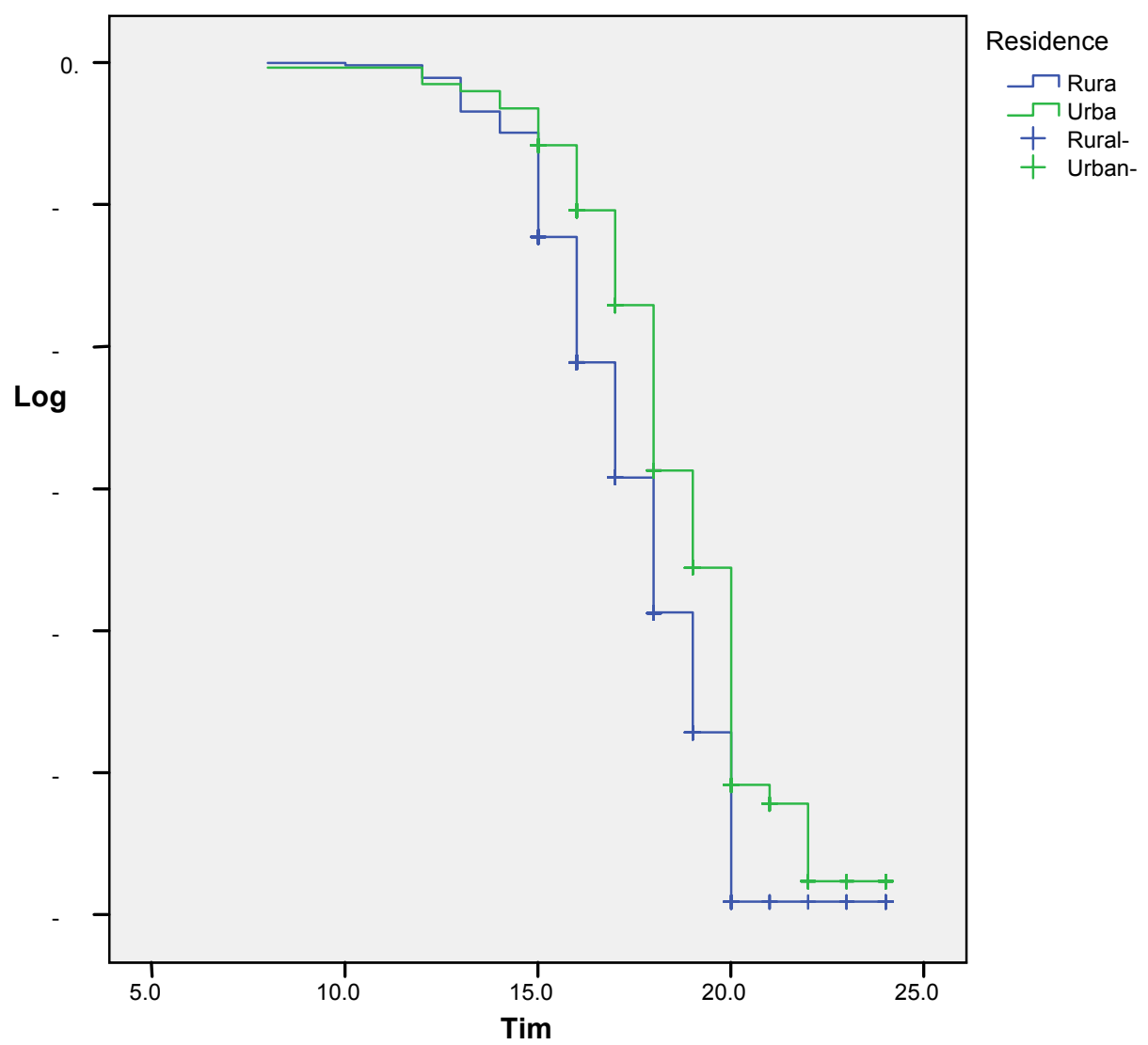

Fig 1: Kaplan Meier curve showing log survival for age at sexual debut for rural and urban female residents in Dessie town and rural Woreda, march nnon

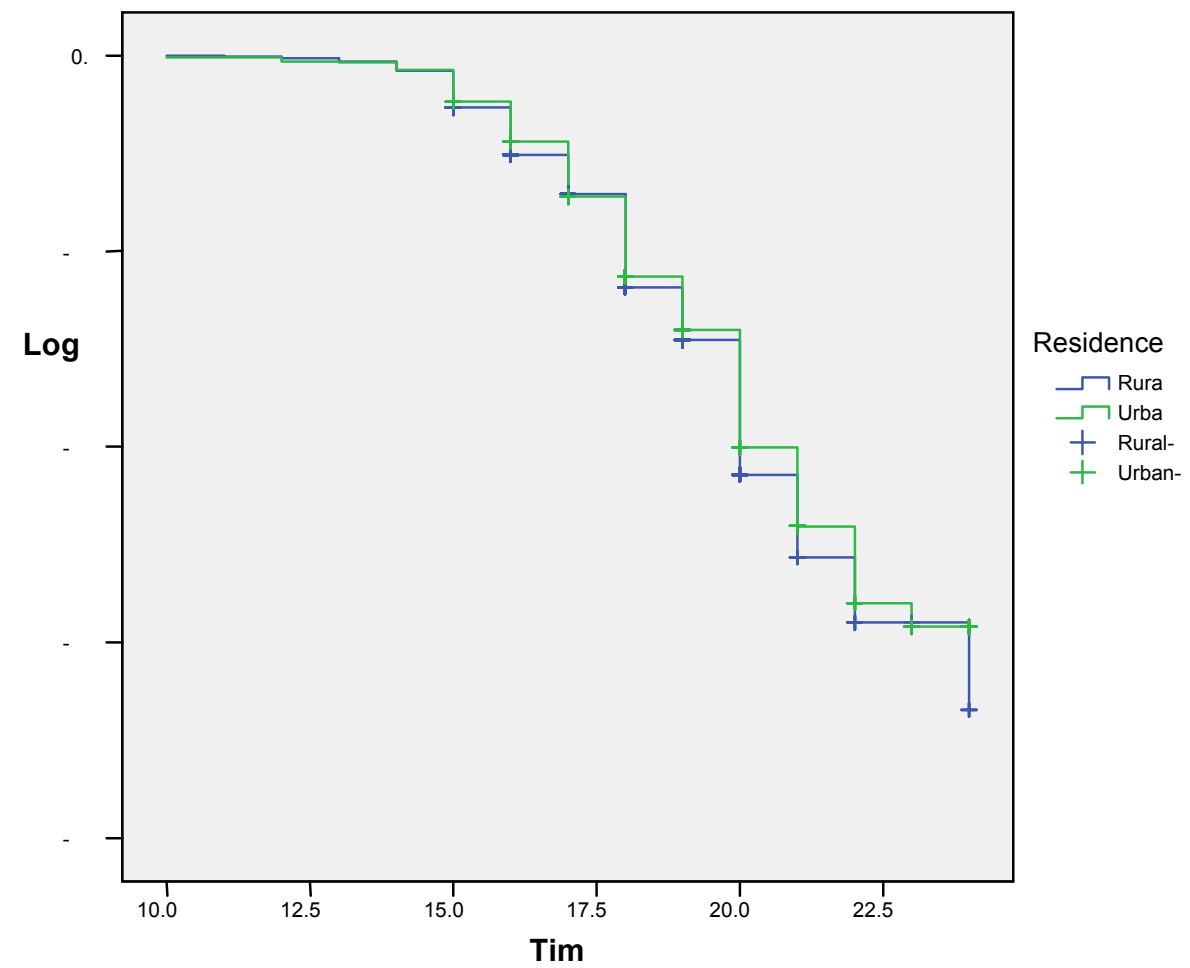

Fig 2: Kaplan Meier curve showing log survival for age at first sexual Debut for male rural and urban youths in Dessie town \& Dessie zurral woreda, march

nnne 


\section{Parent child connectedness and communication}

Respondents score a range of 0 - 12 with mean \pm SD $8.2 \pm 2.96$ scores. The result showed that rural parents have more conservative norms $\mathrm{t}=7.4(\mathrm{P}<0.001)$ than urban parents. However there were no significant mean score differences regarding family connectedness and supervision or guidance between rural and urban parents. Participants who didn't found it easy to discuss about important matters with their mother were more likely to initiate sex-earlier (adjusted OR $[95 \% \mathrm{CI}]=2.48[1.48$, 4.17]). Less family connectedness as measured by less caring attitude and less parent child communication, was an independent predictor of early sexual initiation, adjusted OR $[95 \% \mathrm{CI}]=2.30[1.35,3.91])$. However family conservative norms were not found to be a protective factor for early sexual initiation after adjusted for other family socio-demographic and religious factors (Table 3).

\section{Non- sexual risky behaviours}

Logistic regression analysis showed that youth who chew Khat were two times more likely to initiate sexual

Table 2: Youth socio demographic characteristics by sexual initiation, Dessie town and Dessie Zuria Rural Woreda, Ethiopia, March 2008




Table 3: Associations of family communication and connectedness with early sexual initiation among youths in Dessie town and Dessie Zuria rural Woreda, Ethiopia March 2008

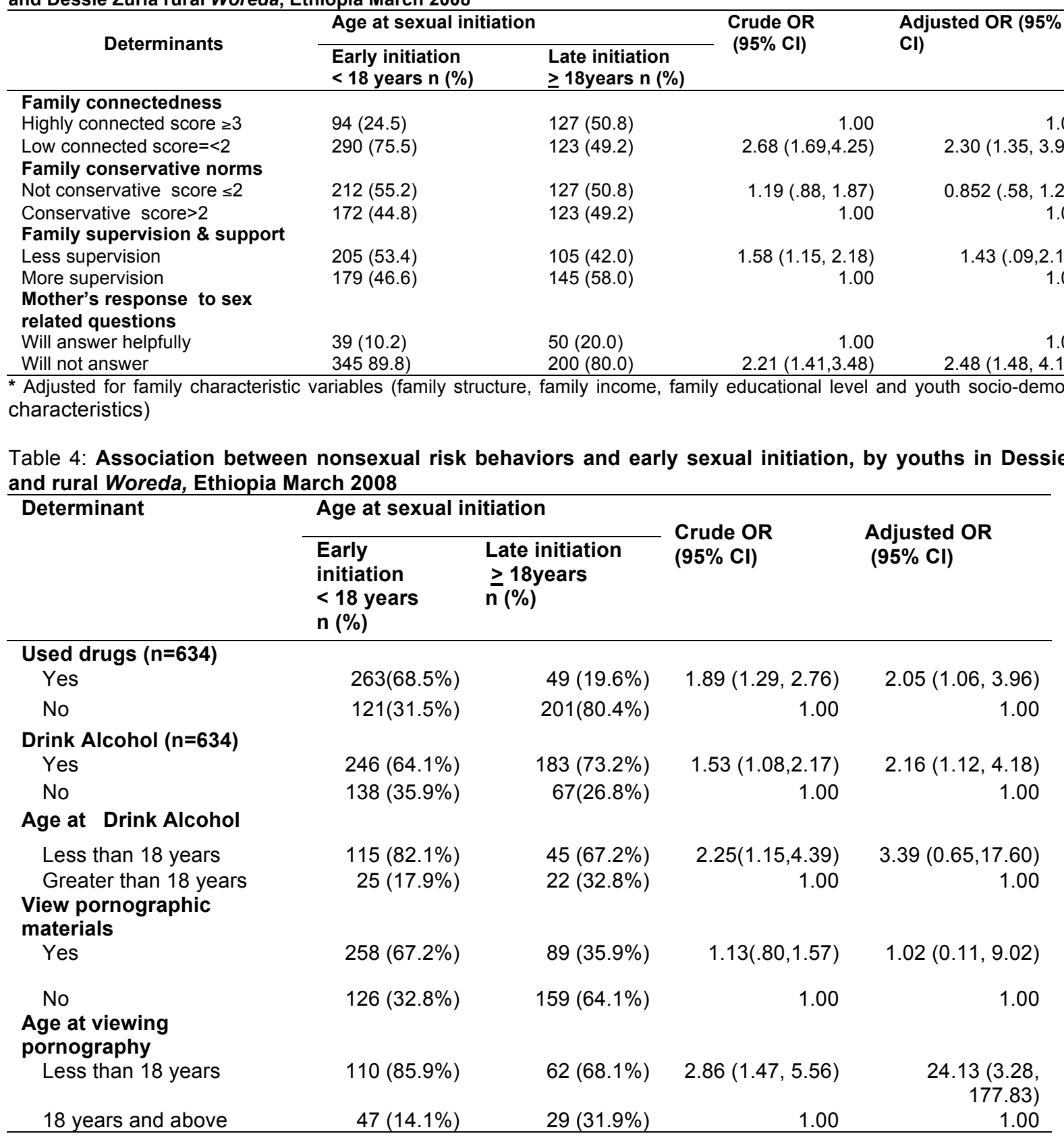

intercourse before 18 years of age (adjusted OR [95\% $\mathrm{CI}]=2.05$ [1.05-3.96]). Those who drink alcohol (adjusted OR $[95 \% \mathrm{CI}]=2.16[1.12-4.18]$ ) also were two times more likely to initiate sexual intercourse before the age of 18 . However viewing pornographic materials were not associated with early initiation. But when we further analyze the age of sexual initiation with the age viewing pornographic materials it was more than 2.9 times higher for those who view pornographic materials at earlier age (less than 18 years) OR $[95 \% \mathrm{CI}]=2.86[1.47,5.56]$ and further when it was adjusted for other variables such as drug abuse and socio-demographic variables it becomes 24 fold, adjusted OR $(95 \% \mathrm{CI})=24.13(3.28,177.83)$ (Table 4).

\section{Discussion}

The Mean \& median age of first sexual initiation in this study is comparable with other previous studies in Ethiopia $(1,3,12,15)$. It is slightly higher than the study done in Kolladuba (15 years) and Gojam (13.5 years). The difference may be explained by the decrease in early marriage which was the main reason for early sexual initiation in rural youths $(16,17)$ due to the recently endorsed family law (18). Another explanation may be AIDS-ravaged countries; campaigns to delay first sexual intercourse may have had an inhibiting effect, particularly among females. Early entry to sexual life has very important implications for the sexual $\&$ reproductive health of youth and reaffirms the need to gear the focus 
of available SRH education programs and services in schools \& at the community for out of school youths not only on the transfer of knowledge but also on skills that help youth delay sexual debut.

The existence of risky sexual practice including premarital sex, unprotected sexual intercourse with non marital partners and sexual intercourse with female commercial sex workers were reported by both urban and rural adolescents. In this study $55 \%$ of urban youths and almost equal proportion (54\%) of rural sexually active youths have more than one partner. In consistent with this finding a survey done among high school youths in Dessie, Bahir Dar, Jimma and Deridawa came up with almost similar findings (52\%) (15). This study showed that the odds of having multiple partnerships were two times higher for those who initiate sexual intercourse at less than 18 years compared to those who initiate sexual intercourse late.

There was a significant variation in condom use among rural and urban boys in this study. A similar study done in Gojam revealed as well contraceptive use including condoms was ten times lower among rural adolescents (16). This may be due to the limited access of condom to rural youths and false self susceptibility perception, such as HIV is not a rural disease considering CSW and urban residents as high risk group.

Our study further identified that family connectedness was highly associated with delay of age at sexual initiating. The result of this study is in agreement with that obtained in a study done in USA which identified that satisfaction in parental relationship and maternal attitudes towards premarital sexual intercourse were inversely associated with early initiation of sexual activity (19). Another similar study examined the association between gender mix of one's friends and early sexual activity. The study reported that having a much greater number of opposite-sex friends at a relatively early age may be related to early sexual intercourse. The transition to adolescence is a period of rapid change, and young adolescents seek peer connections to obtain a stable point of reference during this time (20).

Substance, alcohol use and viewing pornographic materials were other factors associated with early sexual initiation identified by this study. Drug trafficking and drug abuse, although not problems in the past, are becoming more common in Ethiopia (21). According to the MOH Department of Pharmacy report for 2000/01, it is exacerbated by lack of employment opportunities and general feelings of hopelessness. Chat chewers were more than 2-3 times at higher risk to initiate sexual intercourse early than non chewers. Alcohol drinking usually follows khat chewing and might be associated with unprotected sex and early initiation. This finding is supported by similar study in Butajira by Mitikie et al (22).

Those who drink alcohol at least once per month were two times more at risk to initiate sexual intercourse earlier than those who didn't drink alcohol. When further stratified by age those who drank alcohol in less than 18 years were more than 3 times more likely to initiate sex earlier than those who didn't drink alcohol or started drinking lately. A study done among in and out of school Ethiopian youths showed similar results. Beer houses usually provide opportunities to have causal partner. Moreover, sex after drinking alcohol is more likely unprotected because alcohol decreases self control and sexual negotiation skill of adolescents $(5,21)$. Ethiopia's increased openness to Western culture has resulted in the influx of pornographic videos, books, and magazines, whose consumers are mostly young people. Western pornography often preceded sexual initiation and helped the couple to "loosen up" a bit.

In conclusion, the prevalence of early sexual initiation was high; the first sexual intercourse were tend to be unplanned and unprotected. Early initiators were more likely to be involved in subsequent high risk sexual behaviors characterized by multi-partnered sex and no or inconsistent use of condom, casual partnership, and a wide sexual network. In addition non sexual risky behaviours like viewing pornographic materials at earlier age, using drugs and drinking alcohol specially at earlier age are an independent predictors of early sexual initiation.

Delaying sexual debut is the pillar of HIV/STIs prevention among young people. This can be achieved through sexual education programs at earlier life. For school youths it is recommended to incorporate sex education in the curriculum. To address the out of school youths, it is recommended to conduct repeated community conversation programs designed to the level of youths. Moreover, establishing rural reproductive health and anti AIDS clubs is important. Parents and teachers should be trained in a way that enables them to acquire their teens with the necessary skill for sexual negotiation. Strengthening the norm of virginity, which delays sexual intercourse, should be advocated. Equally for those who initiated sex, the skills and service to practice safe sexual life should be availed. It is as well very important to strengthen and implement the family law of Ethiopia.

The strong association between khat, alcohol and viewing pornography entails a need to teach young people, the community, school teachers and parents about the linkage and possible consequences of such exposure to sexual and reproductive health of adolescents. Finally, policy makers should think of setting a legal age for buying alcohol and Khat; and restricting video houses renting and selling pornography films.

Ethiop. J. Health Dev. 2009;23(2) 


\section{Acknowledgements}

It gives us a great honor and privilege to thank CDCEthiopia and the Ethiopian Public Health Association (EPHA) for sponsoring this study. We appreciate all staffs of FGAE North East Ethiopia office, Dessie model youth center. All Dessie Zuria rural Woreda and Dessie town municipality officials deserve special thanks for their kind assistance during data collection period in Dessie town and rural Woreda. Above all our heartfelt thanks go to study participants who spent their precious time in responding to the questionnaire. We are deeply grateful to the following individuals who gave us continuous support and inspiration to finish this study; specially Ato Addis Mazengia, Zelalem Addis, Fiker, Tilahun, Zeleke Alebachew, Ejigayehu Yimam and Sr. Askal Demessie for playing a marvelous role for the success of this study. All Data collectors and the supervisors are highly acknowledged for the utmost effort they put to the quality of this study. Moreover, the University of Gondar and AAU are highly appreciated for covering all other expenses.

\section{References}

1. Govindasamy Pav, Aklilu Kidanu and Hailom Banteyerg: Youth Reproductive Health in Ethiopia. Calverton, Maryland: ORC Macro, 2002.

2. United Nations Children's Fund (UNICEF): Young People and HIV/AIDS; Opportunity in Crisis. New York, NY: UNICEF, 2002.

3. FHI, USAID, Youth Net Assessment Team: Assessment of Youth Reproductive Health Programs in Ethiopia .Addis Ababa, Ethiopia, 2004.

4. Central Statistical Agency [Ethiopia] and ORC Macro: Ethiopia Demographic and Health Survey 2005. Addis Ababa, Ethiopia and Calverton, Maryland, USA, 2006.

5. Barbara S, Monica J, Grant A, Blanc K. The Changing Context of Sexual Initiation in SubSaharan

Africa. www.popcouncil.org/publications/wp/prd/rdwplist.ht $\underline{\mathrm{ml}}$,

6. Kalamuss D, Davidson A, Cohall A, Laraque D, Cassell C: Preventing Sexual Risk Behaviors and Pregnancy among Teenagers: Linking Research and Programs. Perspectives on Sexual and Reproductive Health 2003;35(2):87-93.

7. Ministry of Finance and Economic Development MOFED). The Federal Democratic Republic of Ethiopia: Building on Progress: A Plan for Accelerated and Sustained Development to End Poverty (PASDEP) 2005/06-2009/10. Addis Ababa, 2005.

8. Bongaarts J. Personal Communication, Adolescent and Youth Sexual and Reproductive Health: Charting Directions for a Second Generation of Programming. UNFPA and Population Council, 2002.

9. Attawell K. Going to Scale in Ethiopia: Mobilizing Youth Participation in a National HIV/AIDS
Program. Social \& Scientific Systems, Inc. /the Synergy Project, Washington, D.C, 2004.

10. Frank LM, Michelle M, Fondell $\mathrm{PN}, \mathrm{Hu} \mathrm{LK}$. Kowaleski J, Elizabeth GM. The Determinants of First Sex by Age 14 in a High-Risk Adolescent Population. Family Planning Perspectives 1996;28:13-18.

11. Country-by-Country, Ethiopia: Engender Health. http://www.engenderhealth.org

12. Berhane Y, Yared M, Eleni S, Lawrence G, David W. HIV/AIDS in Ethiopia: An epidemiological synthesis. The World Bank, Washington, DC, April 2008;27-109. Available at: http:/www.worldbank.org/AIDS.

13. Gupta N, Mahy M. Sexual Initiation among Adolescent Women and Men: Trends and Differentials in Sub-Saharan Africa. Demographic and Health Research Division, ORC Macro International. Available at http://WWW.measuredhs. Com.

14. Central Statistical Authority. The 1994 population and housing census of Ethiopia: Results for the Amhara region. Addis Ababa, November 1998.

15. Adamu R, Mulatu MS. Sexual initiation and risk behaviors among Ethiopian high school students. International Conference on AIDS. Int. Conf AIDS. 2000; July 9-14; 13: abstract no. 5610.

16. Seifu A, Fantahun M, Worku A. Reproductive health needs of out-of-school adolescents: Across-sectional comparative study of rural and urban areas in Northwest Ethiopia. Ethiop. J. Health Dev. 2006;20(1):10-17.

17. Ismail S, Bitsuamlak H, Alemu K. igh Risk Sexual Behaviors for STD/HIV, Pregnancies and Contraception among High School Students in a Rural Town, North Western Ethiopia. Ethiop. J. Health Dev. 1997;11(1):29-36.

18. Federal Negarit Gazetta of the Federal Democratic Republic of Ethiopia, The Revised Family Code, Federal Negarit Gazetta Extra Ordinary Issue No. 1/2000 The Revised Family Code Proclamation No. 213/2000, Addis Ababa 4thDay of July, 2000.

19. Stallworth JD, Roofe M, Miller S, Glenn L, Jolly P. Adolescent self-report of reasons for sexual initiation and sexual abstinence. Int. Conf AIDS. 2002 Jul 712; 14: abstract no. E6493.

20. Jennifer C, Wendy C. Mixed-Gender Groups, Dating, and Romantic Relationships in Early Adolescence. Journal of Research on Adolescence. 14(2):185-207.

21. Kebede D, et. Al. Khat and alcohol use and risky sexual behaviour among in-school and out-of-school youth in Ethiopia. BMC Public Health 2005; 5:109. http://www.biomedcentral.com/1471-2458/5/109.

22. Molla M, Berhane Y, Lindtjorn B. Traditional values of virginity and sexual behaviour in rural Ethiopian youth. BMC Public Health 2008;8(1):9. 